
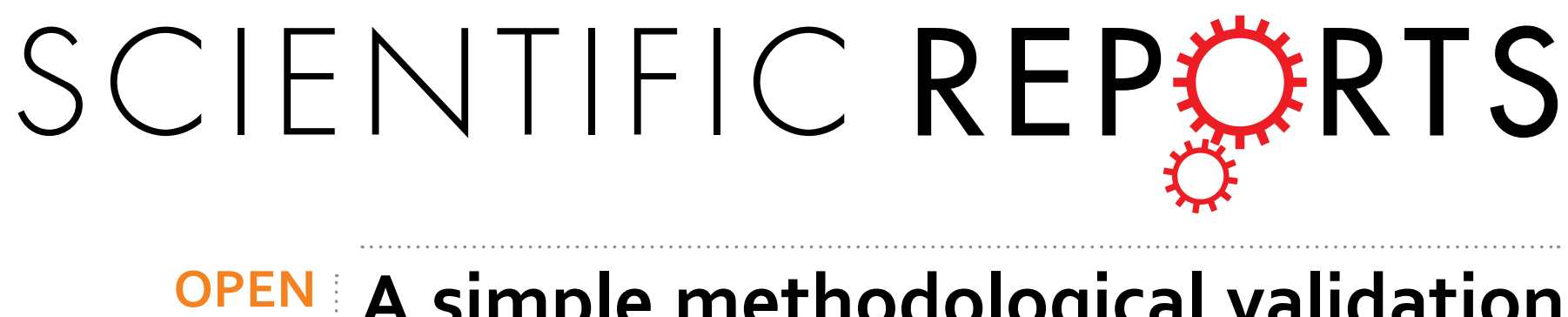

\title{
A simple methodological validation of the gas/particle fractionation of polycyclic aromatic hydrocarbons in ambient air
}

Received: 17 March 2015

Accepted: 03 June 2015

Published: 01 July 2015

\section{Yong-Hyun Kim \& Ki-Hyun Kim}

The analysis of polycyclic aromatic hydrocarbons (PAH) in ambient air requires the tedious experimental steps of both sampling and pretreatment (e.g., extraction or clean-up). To replace pre-existing conventional methods, a simple, rapid, and novel technique was developed to measure gas-particle fractionation of PAH in ambient air based on 'sorbent tube-thermal desorption-gas chromatograph-mass spectrometer (ST-TD-GC-MS)'. The separate collection and analysis of ambient PAHs were achieved independently by two serially connected STs. The basic quality assurance confirmed good linearity, precision, and high sensitivity to eliminate the need for complicated pretreatment procedures with the detection limit (16 PAHs: 13.1 $\pm 7.04 \mathrm{pg}$ ). The analysis of real ambient PAH samples showed a clear fractionation between gas (two-three ringed PAHs) and particulate phases (five-six ringed PAHs). In contrast, for intermediate (four ringed) PAHs (fluoranthene, pyrene, benz[a]anthracene, and chrysene), a highly systematic/gradual fractionation was established. It thus suggests a promising role of ST-TD-GC-MS as measurement system in acquiring a reliable database of airborne PAH.

The presence of polycyclic aromatic hydrocarbons (PAHs) in ambient air is mostly due to anthropogenic processes, particularly incomplete combustion of organic fuels like coal, oil, and gas ${ }^{1}$. The International Agency for Research on Cancer (IARC) has designated some PAHs (e.g., benzo[a]pyrene (BAP), and benz[a]anthracene (BAA)) as known human carcinogens ${ }^{2}$. In particular, BAP is listed as a "level 1 carcinogenic substance"2-4. PAHs are present in the atmosphere in both gaseous and particulate phases. Because the concentrations of PAHs in ambient air are low, e.g., at or below several $\mathrm{ng} \cdot \mathrm{m}^{-3}$ levels, the experimental procedures for their sampling and analysis are sufficiently complicated to suffer from large uncertainties due to low recovery despite large sampling volume ${ }^{5}$.

In order to accurately quantify trace level PAHs in ambient air, a highly sensitive analytical system must be employed, even after acquisition of a large sampling volume. Many researchers have relied on protocols such as the US Environmental Protection Agency (EPA) method to calculate quantities from ambient air samples ${ }^{6-9}$. Accordingly, atmospheric samples should be collected using high-volume air samplers (HVAS), which allow selective collection of gaseous and particulate PAHs on a quartz (or glass) filter and polyurethane foam (PUF) sampler, respectively. In such a sampling system, a flow rate of approximately 0.1 to $1 \mathrm{~m}^{3} \mathrm{~min}^{-1}$ is recommended with a sampling time of about 0.5 to 3 days. The PAHs collected by the filters and PUF sampler are subjected to Soxhlet extraction with appropriate solvent, and the extract is concentrated by an evaporator. Then, the extracts are repeatedly passed through a silica column for purification (over 24 hours). The re-concentrated extracts are analyzed by gas chromatography (GC) coupled with mass spectrometry (MS) or by high-performance liquid chromatography

Department of Civil and Environmental Engineering, Hanyang University, 222 Wangsimni-Ro, Seoul 133-791, Korea. Correspondence and requests for materials should be addressed to K.-H.K. (email: kkim61@hanyang.ac.kr orkkim61@nate.com) 


\begin{tabular}{|c|c|c|c|c|}
\hline \multicolumn{5}{|c|}{ [A] Thermal desorber (model: TD-20, Shimadzu, Japan) } \\
\hline \multicolumn{5}{|l|}{ a. Sampling tube } \\
\hline 1. Trap tube: & \multicolumn{4}{|c|}{ Quartz (length: $90 \mathrm{~mm}$, OD: $6.4 \mathrm{~mm}$, and ID: $4.2 \mathrm{~mm}$ ) } \\
\hline \multirow{2}{*}{ 2. Adsorbent: } & \multicolumn{4}{|c|}{ (1) Quartz wool $25 \mathrm{mg}$ (QW tube); } \\
\hline & \multicolumn{4}{|c|}{$\begin{array}{l}\text { (2) Quartz wool } 10 \mathrm{mg}+\text { Carbopack C (60/80) } 50 \mathrm{mg}+\text { Quartz } \\
\text { wool } 10 \mathrm{mg} \text { (CC tube) }\end{array}$} \\
\hline 3. Desorption flow: & \multicolumn{4}{|c|}{$100 \mathrm{~mL} \cdot \mathrm{min}^{-1}$ (to cold-trap) } \\
\hline 4. Desorption time: & \multicolumn{4}{|l|}{$7 \mathrm{~min}$} \\
\hline 5. Desorption temperature: & \multicolumn{4}{|l|}{$290^{\circ} \mathrm{C}$} \\
\hline \multicolumn{5}{|l|}{ b. Cold-trap } \\
\hline 1. Trap tube: & \multicolumn{4}{|c|}{ Silcosteel (length: $100 \mathrm{~mm}$, OD: $3.2 \mathrm{~mm}$, and ID: $2 \mathrm{~mm}$ ) } \\
\hline 2. Adsorbent: & \multicolumn{4}{|c|}{ Quartz wool $10 \mathrm{mg}+$ Tenax TA $50 \mathrm{mg}$} \\
\hline 3. Adsorption temperature: & \multicolumn{4}{|c|}{$5^{\circ} \mathrm{C}$ (from sampling tube) } \\
\hline 4. Desorption temperature: & \multicolumn{4}{|c|}{$300^{\circ} \mathrm{C}$ (to GC) } \\
\hline 5. Desorption flow: & \multicolumn{4}{|l|}{$16 \mathrm{~mL} \cdot \mathrm{min}^{-1}$} \\
\hline \multicolumn{5}{|l|}{ c. Carrier gas setting } \\
\hline 1. Carrier gas: & \multicolumn{4}{|c|}{ Helium (>99.999\%) } \\
\hline 2. Constant gas flow: & \multicolumn{4}{|l|}{$2 \mathrm{~mL} \cdot \mathrm{min}^{-1}$} \\
\hline 3. Split flow: & \multicolumn{4}{|l|}{$10 \mathrm{~mL} \cdot \mathrm{min}^{-1}$} \\
\hline 4. Purge gas flow: & \multicolumn{4}{|l|}{$2 \mathrm{~mL} \cdot \mathrm{min}^{-1}$} \\
\hline \multicolumn{5}{|c|}{ d. Line and interface temperatures: $300^{\circ} \mathrm{C}$} \\
\hline \multicolumn{5}{|c|}{ [B] Gas chromatography (model: GC-2010, Shimadzu, Japan) } \\
\hline \multirow{2}{*}{ a. Column: } & \multicolumn{4}{|c|}{ DB-5ms (Agilent J\&W, USA) } \\
\hline & \multicolumn{4}{|c|}{ (length $(30 \mathrm{~m})$, diameter $(0.25 \mathrm{~mm})$, and film thickness $(0.25 \mu \mathrm{m}))$} \\
\hline \multirow{2}{*}{ b. Oven settings: } & \multicolumn{4}{|c|}{$80^{\circ} \mathrm{C}(5 \mathrm{~min}) \rightarrow 20^{\circ} \mathrm{C} / \mathrm{min} \rightarrow 300^{\circ} \mathrm{C}(24 \mathrm{~min})$} \\
\hline & \multicolumn{4}{|c|}{ (Total program time $=40 \mathrm{~min})$} \\
\hline \multicolumn{5}{|c|}{ [C] Mass spectrometry (model: GCMS-QP2010 ultra, Shimadzu, Japan) } \\
\hline a. Ionization mode: & $\mathrm{EI}(70 \mathrm{eV})$ & d. TIC scan range: & $35 \sim 600 \mathrm{~m} / \mathrm{z}$ & \\
\hline b. Ion source temperature: & $280^{\circ} \mathrm{C}$ & e. Scan speed: & 1250 & \\
\hline c. Interface temperature: & $280^{\circ} \mathrm{C}$ & & & \\
\hline
\end{tabular}

Table 1. Operational conditions for the analysis of 16 target PAHs using the TD-GC-MS system in this work.

(HPLC) equipped with a fluorescence detector (FLD $)^{6,7,10}$. In addition to this complicated pretreatment procedure, the US EPA method further requires the use of internal standards to balance low recovery stemming from complicated extraction procedures.

In this study, a highly simplified technique for the analysis of $\mathrm{PAH}$ in ambient air was developed and validated using sorbent tube (ST) sampling and thermal desorption (TD)-GC-MS analysis (Table 1). We were able to accurately describe the distribution of PAH in different phases with reliable QA data and to eliminate complicated sampling and pretreatment procedures. To this end, the minimum range of air sampling volume (e.g., less than several $\mathrm{m}^{3}$ ) was first investigated in order to create optimal conditions for the PAH analysis by ST/TD-GC-MS. The reliability of each process was examined further through the assessment of basic QA parameters (detectability, recovery, and breakthrough volume). This method was employed to explore the fractionation patterns between gaseous and particulate phases from a series of real ambient samples.

\section{Results and Discussion}

Results of PAH calibration experiments based on the ST method. In order to assess the reliability of our ST method for PAH analysis, the calibration results of 16 target PAHs were obtained by analyzing the liquid-working standard (L-WS) using a TD-GC-MS system (Table S1). All target PAHs had fairly good linearity with $\mathrm{R}^{2}$ values $>0.99\left(\right.$ mean $\left.\mathrm{R}^{2} \pm \mathrm{SD}(\mathrm{n}=16)=0.9987 \pm 0.0015\right)$. The analytical precision of PAH determination was also assessed in terms of relative standard error (RSE, \%) using triplicate analyses of the third calibration point of the L-WS $\left(\mathrm{BAP}=4.98 \mathrm{ng} \cdot \mu \mathrm{L}^{-1}\right.$; analytical volume $\left.=1 \mu \mathrm{L}\right)$. The 


\begin{tabular}{|c|c|c|c|c|c|c|c|c|c|c|}
\hline \multirow[b]{3}{*}{ Order } & \multirow{3}{*}{$\begin{array}{l}\text { Method } \\
\text { Code }^{a} \\
\end{array}$} & \multicolumn{4}{|c|}{ Detection limit (pg) } & \multicolumn{4}{|c|}{ Pretreatment procedures } & \multirow[b]{3}{*}{ Ref. } \\
\hline & & \multicolumn{2}{|c|}{ Mean \pm SD } & \multicolumn{2}{|c|}{ Min-Max } & \multirow{2}{*}{$\begin{array}{c}\begin{array}{c}\text { Used } \\
\text { filter }\end{array} \\
\begin{array}{c}\text { area } \\
(\%)\end{array}\end{array}$} & \multirow{2}{*}{$\begin{array}{c}\text { Extracted } \\
\begin{array}{c}\text { volume } \\
(\mu \mathrm{L})\end{array}\end{array}$} & \multirow{2}{*}{$\begin{array}{c}\text { Injection } \\
\begin{array}{c}\text { volume } \\
(\mu \mathrm{L})\end{array}\end{array}$} & \multirow{2}{*}{$\begin{array}{c}\text { Expected } \\
\begin{array}{c}\text { recovery } \\
(\%)\end{array}\end{array}$} & \\
\hline & & MDL & LOD & MDL & LOD & & & & & \\
\hline 1 & T-AbBd-4- $\alpha$ & $13.1 \pm 7.04$ & $0.76 \pm 0.20$ & $5.19-27.0$ & $0.57-1.23$ & 100 & - & - & 100 & This study (2014) \\
\hline 2 & T-Aa-4- $\alpha$ & & $122 \pm 69.0$ & & & 25 & - & - & 25 & Bates et al..$^{18}$ \\
\hline 3 & T-AcBe-4- $\alpha$ & & $1.86 \pm 0.79$ & & $0.86-3.74$ & 100 & - & - & 100 & Wauters et al..$^{19}$ \\
\hline 4 & T-AcBe-4- $\alpha$ & & $67.9 \pm 83.5$ & & $1.44-259$ & 100 & - & - & 100 & Lazarov et al..$^{20}$ \\
\hline 5 & $C-A b-1-\alpha$ & $208 \pm 138$ & & $66.2-497$ & & 50 & 100 & 2 & 1 & Bari et al. ${ }^{15}$ \\
\hline 6 & C-AbBd-1- $\alpha$ & & & $9.21-25.3$ & & 100 & 1,000 & 2 & 0.2 & Ma et al..$^{13}$ \\
\hline 7 & C-AbBd-1- $\alpha$ & & & & $6.9-157$ & 100 & 500 & 1 & 0.2 & Sheu et al. ${ }^{28}$ \\
\hline 8 & C-AaBd-1- $\alpha$ & & & $200-1,000$ & & 100 & 1,000 & 1 & 0.1 & Anthwal et al..$^{14}$ \\
\hline 9 & C-AaBd-1- $\gamma$ & & & & $0.58-7.99$ & 100 & 1,000 & 20 & 2 & Albinet et al. ${ }^{17}$ \\
\hline 10 & 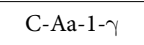 & & $2.09 \pm 1.11$ & & $0.70-4.30$ & 0.28 & 500 & 20 & 0.011 & Okuda et al..$^{16}$ \\
\hline 11 & C-AbBd-1- $\beta$ & & $330 \pm 116$ & & $220-440$ & 100 & 500 & 10 & 2 & Yamasaki et al. ${ }^{29}$ \\
\hline 12 & C-Aa-3- $\alpha$ & & $566 \pm 336$ & & $20-1,160$ & 100 & - & - & - & $\begin{array}{c}\text { Menezes and de Lourdes } \\
\text { Cardeal }^{30}\end{array}$ \\
\hline 13 & C-Ac-2- $\gamma$ & & $7.69 \pm 4.54$ & & $2.51-14.8$ & 100 & 1,000 & 20 & 2 & Schnelle-Kreis et al. ${ }^{31}$ \\
\hline
\end{tabular}

Table 2. Comparison of detection limits and pretreatment procedures for PAH analysis in different

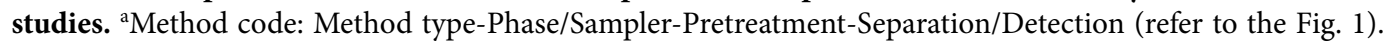

RSE values of target PAHs were fairly low, with a mean of $0.57 \pm 0.22 \%$. In this way, accurate and reliable QA data for PAH analysis were acquired through the ST-based analysis of liquid-phase PAH standards.

Detectability of PAHs in terms of LOD and MDL. In this study, the detection limits (DL) of target PAHs were determined based on the ST method using the L-WS in two common ways: (1) method detection limit (MDL) and (2) limit of detection (LOD) (Table S2). Although the MDL is more representative of actual or practical detection limits than the LOD, the LOD values were commonly reported as the ultimate limit of detection (as their DL) in many previous studies of PAHs. It should however be noted that the use of the LOD values can be misleading in a practical sense, as they tend to be significantly lower than the MDL values ${ }^{11,12}$. In this research, to assess the gaps between the two contrasting DL concepts, the MDL values were also assessed according to the relevant US EPA guidelines. To this end, seven repetitive analyses were completed using a diluted L-WS $\left(\mathrm{BAP}=49.8 \mathrm{pg} \cdot \mu \mathrm{L}^{-1}: 25\right.$-fold dilution of the lowest concentration standard) in order to determine the standard deviation (SD) in peak areas. The resulting SD values were then multiplied by 3.14 (Student's t-value at the $99.9 \%$ confidence interval) and divided by the response factor (RF) to yield the MDL in mass quantity (pg). On the other hand, LOD values were determined as three times the standard deviation of background noise $(n=7)$. The MDL values for 16 target PAHs were found to range from $5.19 \mathrm{pg}$ (BKF) to $27.0 \mathrm{pg}$ (ACL) (mean $13.1 \pm 7.04 \mathrm{pg}$ ), while the LOD values were in the range of $0.57 \mathrm{pg}$ (DBA) to $1.23 \mathrm{pg}$ (FLR) (mean $=0.76 \pm 0.20 \mathrm{pg}$ ). A wide range of DL values of PAHs have been reported, from several pg to ng levels. As shown in Table 2, the DL values of this study are considerably lower than those in many previous studies.

For example, $\mathrm{Ma}$ et al. ${ }^{13}$ analyzed PAHs using the US EPA method (HVAS sampling, extraction-cleanup-concentration (E-C-C) pretreatments, and GC-MS detection) and reported MDL values of 9.21-25.3 pg, which are similar to those of the present study (the range of MDL for 16 PAHs: 5.19$27.0 \mathrm{pg}$ ). In contrast, using the same analytical method as Ma et al. ${ }^{13}$, others have reported MDL values one to two orders of magnitude higher (66.2-497 pg and $200-1,000 \mathrm{pg}$, respectively) ${ }^{14,15}$. Interestingly, some researchers who employed an HPLC-FLD system after the E-C-C pretreatment procedures presented LOD values of $0.58-7.99 \mathrm{pg}$ and $0.70-4.30 \mathrm{pg}$, respectively ${ }^{16,17}$. As such, these HPLC-based LOD values appear to be highly comparable to our results (the range of LOD for 16 PAHs: $0.57-1.23 \mathrm{pg}$ ). All types of methodological options involved in sampling/pretreatment/detection are summarized in Fig. 1. In Table 3, the different detection limits are also compared using the clarification criteria introduced in Fig. 1 .

Comparison of detectabilities associated with sampling and pretreatment procedures. It is interesting to consider explanations for the observed differences in detectability of PAHs between different studies. The DL values for PAHs in this study were similar to or somewhat lower than those in many previous studies, probably due to differences in total sampling volume vs. the amount actually delivered into the detection system. Note that most previous studies generally relied on large sampling volumes (e.g., exceeding $1,000 \mathrm{~m}^{3}$ ) to quantify ambient PAHs at sub $\mathrm{ng} \cdot \mathrm{m}^{-3}$ levels (Table 3 ). If PAH samples are 


\begin{tabular}{|l|l|l|c|}
\hline Method type & Phase / Sampler & Pretreatment & $\begin{array}{c}\text { Separation / } \\
\text { Detection }\end{array}$ \\
\hline
\end{tabular}

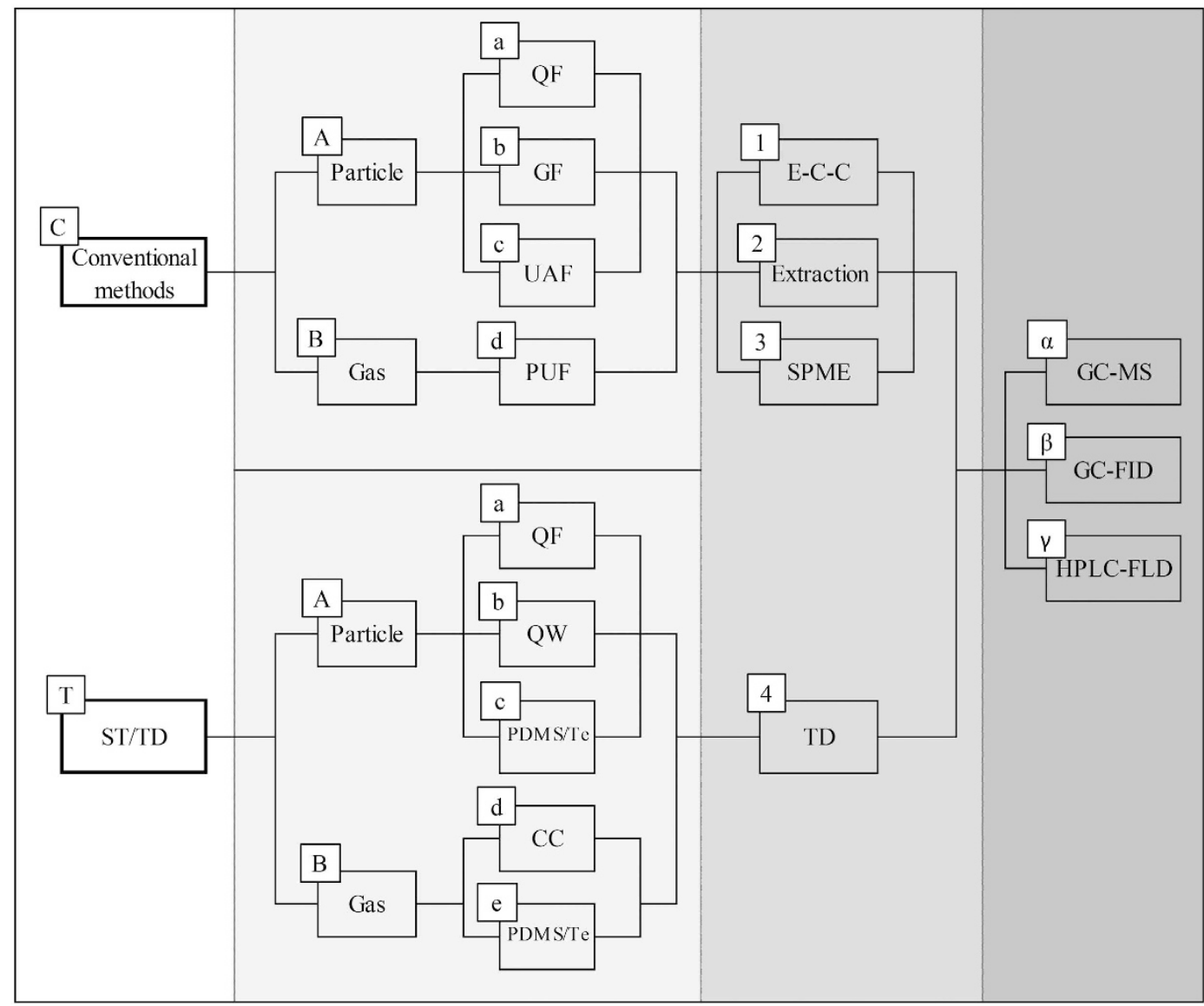

Figure 1. Flow chart of analytical options for the quantitation of ambient PAH between gas and particles. Abbreviation: A. Sampler $(\mathrm{QF}=$ quartz filter, $\mathrm{GF}=$ glass filter, $\mathrm{UAF}=$ ungreased aluminium foil, $\mathrm{PUF}=$ polyurethane foam, $\mathrm{QW}=$ quartz wool tube, $\mathrm{PDMS}=$ polydimethylsiloxane, $\mathrm{CC}=$ Carbopack $\mathrm{C}$ tube, and $\mathrm{Te}=$ Tenax TA); B. Pretreatment $(\mathrm{E}-\mathrm{C}-\mathrm{C}=$ Extraction-Cleanup-Concentration, SPME $=$ Utilized direct immersion-Cold fiber-Solid phase microextraction, and TD = thermal desorption); and C. Separation/ Detection $(\mathrm{GC}=$ gas chromatography; $\mathrm{HPLC}=$ high-performance liquid chromatography, $\mathrm{MS}=$ mass spectrometry, FLD = fluorescence, and FID = flame ionization detector).

subject to the E-C-C pretreatment procedures (US EPA method), the actual mass for quantification is substantially reduced as follows. First, only certain fractions of the filter used for PAH collection are included due in the extraction. Hence this approach is subject to dual loss effects (only a small fraction of the sample is used for the extraction and subsequent loss due to treatment) that lead to a noticeable reduction in MDL under the ideal recovery conditions for PAHs at $0.01 \%$ to $2 \%$ (Table 2).

To obtain sufficient quantities of analytes (PAHs), a high-volume air sampler has commonly been employed to collect air samples of 100 to $1,000 \mathrm{~m}^{3}$ levels at high flow rates $\left(>100 \mathrm{~m}^{3} \mathrm{~min}^{-1}\right)$ over one to two days. In the present research, the volume size of PAH samples was reduced dramatically to $1.44 \mathrm{~m}^{3}$ (flow rate of $2 \mathrm{~L} \mathrm{~min}^{-1}$ ) by employing a low flow rate mini-vacuum pump. Despite this small sample volume, the absolute mass collected for each sample amounted to $17.8 \mathrm{pg}$ (BKF) 161 ng (NAP), which is still about 3 to 1,500 times larger than the MDL values. We are currently extending our efforts to improve ST sampling more efficiently in order to considerably shorten the sampling time for rapid monitoring of PAHs.

Bates et al. ${ }^{18}$ analyzed PAHs using a procedure similar to our TD-GC-MS method. Although they used a similar system for PAH analysis, their methods were limited in that the media used for collecting air samples (filter) and for analyzing standards (sorbent tube) were different from each other. They relied on LVAS to collect $24 \mathrm{~m}^{3}$ of air on a quartz filter. However, as they were unable to establish the optimal conditions of ST-TD-GC-MS (e.g., sufficiently high temperature for sample transfer in a TD system), their DL values for the PAH analysis are considerably higher than ours (mean LOD: (1) Bates et al. ${ }^{18}=122 \pm 69.0 \mathrm{pg}$ vs. (2) This study $=0.76 \pm 0.20 \mathrm{pg}$ ). The use of ST-TD-GC-MS system for the analysis of airborne PAHs can also be found from some other previous studies ${ }^{19,20}$. In those studies, the ST 


\begin{tabular}{|c|c|c|c|c|c|c|c|c|c|c|}
\hline \multirow{3}{*}{$\begin{array}{l}\text { Or- } \\
\text { der }\end{array}$} & \multirow{3}{*}{$\begin{array}{c}\text { Method } \\
\text { Code }^{a} \\
\end{array}$} & \multirow{3}{*}{\begin{tabular}{|c|}
$\begin{array}{c}\text { No. } \\
\text { of }\end{array}$ \\
target \\
PAHs \\
\end{tabular}} & \multirow[b]{3}{*}{ Rings } & \multicolumn{6}{|c|}{ Sampling conditions } & \multirow[b]{3}{*}{ Ref. } \\
\hline & & & & \multirow[b]{2}{*}{ Pump $^{b}$} & \multirow[b]{2}{*}{ Site } & \multirow{2}{*}{$\begin{array}{c}\text { Period } \\
\text { (starting time) }\end{array}$} & \multirow{2}{*}{$\begin{array}{c}\text { Flow rate } \\
\left(\mathrm{m}^{3} \cdot \mathrm{min}^{-1}\right)\end{array}$} & \multirow{2}{*}{$\begin{array}{c}\text { Time } \\
(\mathrm{hr})\end{array}$} & \multirow{2}{*}{$\begin{array}{c}\text { Volume } \\
\left(\mathbf{m}^{3}\right)\end{array}$} & \\
\hline & & & & & & & & & & \\
\hline 1 & T-AbBd-4- $\alpha$ & 16 & $2-6$ & Sibata MP300 & Seoul, Korea (7th building) & $\begin{array}{l}\text { 7 11 Oct. } 2014 \\
(00: 00)\end{array}$ & 0.002 & 12 & 1.44 & This study (2014) \\
\hline 2 & T-Aa-4- $\alpha$ & 9 & $4-6$ & LVAS & Bari, Italy (street with traffic) & $\mathrm{NI}^{c}$ & 0.01667 & 24 & 24 & Bates, et al..$^{18}$ \\
\hline 3 & T-AcBe-4- $\alpha$ & 16 & $2-6$ & $\begin{array}{l}\text { Gilair } 3 \\
\text { personal air } \\
\text { sampling } \\
\text { pump }\end{array}$ & Ghent, Belgium (Lab campus) & $\begin{array}{l}\text { Apr. } 2005 \sim \text { Mar. } \\
2006\end{array}$ & 0.0001 & 24 & 0.144 & Wauters et al..$^{19}$ \\
\hline 4 & T-AcBe-4- $\alpha$ & 16 & $2-6$ & GSA SG350 & Antwerp, Belgium & Mar. May 2012 & 0.000333 & 24 & 480 & Lazarov et al. ${ }^{20}$ \\
\hline 5 & $C-A b-1-\alpha$ & 21 & $2-6$ & LVAS & Dettenhausen, Germany & $\begin{array}{l}1 \text { Nov. } 2005 \sim 31 \\
\text { Mar } 2006\end{array}$ & 0.038 & 48 and 72 & 110 and 166 & Bari, et al. ${ }^{15}$ \\
\hline 6 & C-AbBd-1- $\alpha$ & 16 & $2-6$ & HVAS & Harbin, China (Northeastern) & $\begin{array}{l}5 \text { Aug. } 2008 \sim 29 \\
\text { July } 2009\end{array}$ & 0.8 & 24 & 1,152 & $\mathrm{Ma}$, et al. ${ }^{13}$ \\
\hline 7 & C-AbBd-1- $\alpha$ & 21 & $2-6$ & HVAS & Center of Tainan City, Taiwan & $\begin{array}{c}21 \text { Jan. } 25 \text { May } \\
1994\end{array}$ & 0.69 & 24 & 1,000 & Sheu, et al..$^{28}$ \\
\hline 8 & C-AaBd-1- $\alpha$ & 17 & $2-6$ & HVAS & Seoul, Korea & Feb. July 2009 & 0.8 & 24 & 1,152 & Anthwal, et al. ${ }^{14}$ \\
\hline 9 & C-AaBd-1- $\gamma$ & 15 & $3-7$ & HVAS & $\begin{array}{l}\text { Marseilles area, South of } \\
\text { France }\end{array}$ & $\begin{array}{l}22 \sim 29 \text { July } 2004 \\
(08: 00)\end{array}$ & 0.5 & 12 & 360 & Albinet, et al..$^{17}$ \\
\hline 10 & C-Aa-1- $\gamma$ & 16 & $3-7$ & HVAS & Beijing, China & $\begin{array}{l}\text { Sept. 2003 Apr. } \\
2005(11: 00)\end{array}$ & 0.8 & 24 & 1,152 & Okuda, et al. ${ }^{16}$ \\
\hline 11 & C-AbBd- $1-\beta$ & 17 & $3-6$ & HVAS & Osaka, Japan & $\begin{array}{l}\text { 7, Nov. } 1977 \sim 9 \text {, } \\
\text { Nov. } 1978\end{array}$ & 0.75 & 24 & 1,080 & Yamasaki, et al. ${ }^{29}$ \\
\hline 12 & C-Aa-3- $\alpha$ & 16 & $2-6$ & HVAS & $\begin{array}{c}\text { Divinopolis and Minas Gerais, } \\
\text { Brazil }\end{array}$ & Nov. 2009 & 1.03 & 24 & 1,488 & $\begin{array}{l}\text { Menezes and de } \\
\text { Lourdes Cardeal }^{30}\end{array}$ \\
\hline 13 & 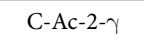 & 7 & $3-6$ & LPI & Munich, Germany & $1996 \sim 1998$ & 0.02971 & 23.5 & 42 & Schnelle-Kreis, et al. ${ }^{31}$ \\
\hline 14 & C-AbBd-1- $\alpha$ & 11 & $3-6$ & HVAS & Chicago and Michigan, USA & July 1994 (08:00) & $0.5-0.8$ & 12 & $360-576$ & Simcik, et al. ${ }^{21}$ \\
\hline 15 & C-AbBd-1- $\alpha$ & 16 & $2-6$ & HVAS & Beijing, China & $\begin{array}{l}6 \text { Sept. } 2008 \sim 29 \\
\text { July } 2009\end{array}$ & 0.8 & 24 & 1,152 & $\mathrm{Ma}$, et al. ${ }^{22}$ \\
\hline
\end{tabular}

Table 3. Overview of sampling conditions for PAHs with several types of analytical methods. ${ }^{\text {a Method }}$ code: Method type-Phase/Sampler-Pretreatment-Separation/Detection (refer to the Fig. 1). ${ }^{\text {b}}$ LVAS $=$ low-

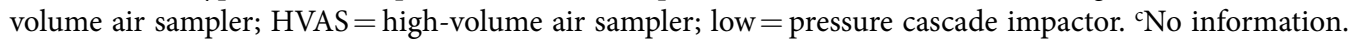

packed with Polydimethylsiloxane foam filter and Tenax TA was used to collect the PAH samples in air. In the case of Wauters et al. ${ }^{19}$, the DL values for PAHs were significantly low with mean $1.86 \pm 0.79 \mathrm{pg}$ (LOD, $n=16$ ), but they did not present the MDL values. In addition, their quantitation was not made separately for each of particle and gaseous phase, as a single tube (packed with PDMS and Tenax TA adsorbent) was used to collect PAH in both phases for the TD-based analysis.

Test of breakthrough volume of PAHs on the ST. In this study, ambient PAHs were collected on the ST using a small vacuum pump. A total of $1.44 \mathrm{~m}^{3}$ of air was drawn for 12 hours at an air flow rate of $2 \mathrm{~L} \mathrm{~min} \mathrm{~m}^{-1}$. The required sample volume for PAH analysis is quite small $\left(1.44 \mathrm{~m}^{3}\right)$ compared to those in most previous studies, but the breakthrough volume (BTV) of PAHs on the ST sampler needs to be assessed for accurate quantification. To examine the BTV of PAHs on the ST, $\mathrm{N}_{2}$ gas was purged to the ST with six different volumes after loading the L-WS.

Table S3 shows the mass recovery of PAHs in the CC tube with different purge volumes in order to test the BTV. The PAH mass recovery was calculated using the RF values (ng ${ }^{-1}$ ) obtained by L-WS analysis: (1) Measured mass (ng) = Peak area / RF value $\left(n g^{-1}\right)$ and (2) Relative recovery (\%) = Measured mass (ng) / Injected mass (ng) $* 100$. For the total purge volume of $1 \mathrm{~L}$, the recovery of PAH averaged 72.6 ( $\pm 3.89 \%: S D)$. Likewise, at the low purge volume of $1 \mathrm{~L}$, adsorption-partitioning equilibria were not attained between analytes and sorbents in the CC tube, resulting in poor recovery. However, if the purge volume increased above 9L, all target PAHs had sufficiently high recoveries ( $>99 \%$; mean recovery $=99.5 \pm 0.50 \%)$. These high $\mathrm{PAH}$ recoveries were maintained up to the maximum tested purge volume of $2.52 \mathrm{~m}^{3}$ (mean recovery $=99.1 \pm 1.29 \%$ ). The results of our BT point test did not directly identify the BT but confirmed the importance of a purge step to ensure optimal recovery. As a result, we were able to predict that the BT of PAHs on the ST should not occur during routine sampling (e.g., up to $1.44 \mathrm{~m}^{3}$ of sample volume). 


\begin{tabular}{|c|c|c|c|c|c|c|c|c|c|c|c|c|c|c|c|c|c|c|c|}
\hline \multirow[b]{4}{*}{ Order } & \multirow{4}{*}{$\begin{array}{l}\text { Sample } \\
\text { code }^{\mathrm{a}}\end{array}$} & $\begin{array}{l}\text { Com- } \\
\text { pound: }\end{array}$ & NAP & ACL & ACN & FLR & PHN & ANT & FLT & PYR & BAA & $\mathrm{CHY}$ & BBF & BKF & BAP & ICP & DBA & BGP & \multirow[b]{4}{*}{ Sum } \\
\hline & & $\underset{(\mathrm{g} / \mathrm{mole}):}{\mathrm{MW}}$ & 128 & 152 & 154 & 166 & 178 & 178 & 202 & 202 & 228 & 228 & 252 & 252 & 252 & 276 & 278 & 276 & \\
\hline & & Rings: & 2 & 2 & 2 & 3 & 3 & 3 & 4 & 4 & 4 & 4 & 5 & 5 & 5 & 6 & 5 & 6 & \\
\hline & & Rt (min): & 10.77 & 13.08 & 13.30 & 13.96 & 15.20 & 15.27 & 16.74 & 17.07 & 19.10 & 19.18 & 21.95 & 22.04 & 23.09 & 28.34 & 28.49 & 29.93 & \\
\hline \multicolumn{20}{|c|}{ A. Concentration $\left(\mathrm{ng} \cdot \mathrm{m}^{-3}\right)$} \\
\hline 1 & WQ-1 & & 0.10 & 0.02 & 0.01 & 0.03 & 0.23 & 0.03 & 0.54 & 0.46 & 0.16 & 0.27 & 0.5363 & 0.1278 & 0.1817 & 0.2248 & 0.0346 & 0.2669 & 3.18 \\
\hline 2 & CC-1 & & 35.6 & 1.41 & 4.77 & 3.54 & 6.00 & 0.18 & 1.16 & 0.80 & 0.05 & 0.08 & 0.0735 & 0.0159 & 0.0212 & 0.0257 & 0.0086 & 0.0326 & 53.8 \\
\hline 3 & WQ-2 & & 0.12 & 0.02 & 0.01 & 0.03 & 0.26 & 0.01 & 0.64 & 0.49 & 0.15 & 0.28 & 0.5222 & 0.1640 & 0.1785 & 0.1981 & 0.0289 & 0.2501 & 3.32 \\
\hline 4 & $\mathrm{CC}-2$ & & 64.4 & 1.44 & 5.57 & 4.34 & 5.79 & 0.29 & 1.03 & 0.70 & 0.05 & 0.08 & 0.0954 & 0.0172 & 0.0253 & 0.0379 & 0.0086 & 0.0272 & 83.9 \\
\hline 3 & WQ-3 & & 0.18 & 0.02 & 0.03 & 0.03 & 0.28 & 0.03 & 0.61 & 0.53 & 0.11 & 0.25 & 0.3976 & 0.0824 & 0.1175 & 0.1261 & 0.0483 & 0.1992 & 3.02 \\
\hline 4 & CC-3 & & 62.0 & 1.60 & 7.10 & 4.24 & 7.15 & 0.21 & 1.41 & 0.87 & 0.05 & 0.08 & 0.0969 & 0.0180 & 0.0278 & 0.0344 & 0.0086 & 0.0420 & 84.9 \\
\hline 3 & WQ-4 & & 0.16 & 0.07 & 0.06 & 0.03 & 0.37 & 0.04 & 0.97 & 0.92 & 0.38 & 0.67 & 1.3199 & 0.3500 & 0.3494 & 0.5498 & 0.2430 & 0.5765 & 7.06 \\
\hline 4 & CC-4 & & 94.2 & 2.08 & 10.67 & 6.80 & 8.26 & 0.48 & 1.14 & 0.81 & 0.06 & 0.10 & 0.1086 & 0.0288 & 0.0271 & 0.0350 & 0.0191 & 0.0380 & 124.8 \\
\hline 5 & WQ-5 & & 0.11 & 0.02 & 0.02 & 0.04 & 0.26 & 0.01 & 0.68 & 0.43 & 0.09 & 0.16 & 0.2291 & 0.0779 & 0.0992 & 0.0760 & 0.0086 & 0.1158 & 2.41 \\
\hline 6 & CC-5 & & 16.4 & 0.86 & 2.15 & 2.04 & 4.55 & 0.10 & 0.79 & 0.60 & 0.03 & 0.05 & 0.0374 & 0.0142 & 0.0225 & 0.0080 & 0.0086 & 0.0113 & 27.7 \\
\hline \multicolumn{20}{|c|}{ B. Total concentration $\left(\mathrm{ng} \cdot \mathrm{m}^{-3}\right)$} \\
\hline 1 & 1 & & 35.7 & 1.41 & 4.77 & 3.57 & 6.23 & 0.21 & 1.70 & 1.26 & 0.21 & 0.35 & 0.61 & 0.14 & 0.20 & 0.25 & 0.03 & 0.30 & 56.9 \\
\hline 2 & 2 & & 64.6 & 1.44 & 5.57 & 4.37 & 6.05 & 0.31 & 1.67 & 1.19 & 0.20 & 0.35 & 0.62 & 0.18 & 0.20 & 0.24 & 0.03 & 0.28 & 87.3 \\
\hline 3 & 3 & & 62.1 & 1.60 & 7.13 & 4.27 & 7.43 & 0.23 & 2.02 & 1.40 & 0.16 & 0.34 & 0.49 & 0.10 & 0.15 & 0.16 & 0.05 & 0.24 & 87.9 \\
\hline 4 & 4 & & 94.3 & 2.15 & 10.7 & 6.83 & 8.63 & 0.52 & 2.12 & 1.72 & 0.44 & 0.76 & 1.43 & 0.38 & 0.38 & 0.58 & 0.26 & 0.61 & 132 \\
\hline \multirow[t]{3}{*}{5} & 5 & & 16.6 & 0.86 & 2.17 & 2.08 & 4.82 & 0.11 & 1.47 & 1.02 & 0.13 & 0.21 & 0.27 & 0.09 & 0.12 & 0.08 & 0.0086 & 0.12 & 30.1 \\
\hline & & Mean & 54.7 & 1.49 & 6.1 & 4.22 & 6.6 & 0.28 & 1.79 & 1.32 & 0.23 & 0.40 & 0.683 & 0.179 & 0.210 & 0.262 & 0.075 & 0.310 & 78.8 \\
\hline & & SD & 29.7 & 0.46 & 3.16 & 1.72 & 1.45 & 0.15 & 0.27 & 0.26 & 0.12 & 0.21 & 0.440 & 0.117 & 0.100 & 0.194 & 0.106 & 0.185 & 38.2 \\
\hline \multicolumn{20}{|c|}{ B. Distribution (\%) } \\
\hline \multirow[t]{2}{*}{1} & 1 & Particle & 0.29 & $\mathrm{NA}^{\mathrm{c}}$ & NA & 0.85 & 3.64 & 12.8 & 31.8 & 36.6 & 75.4 & 76.0 & 87.9 & 88.9 & 89.6 & 89.8 & NA & 89.1 & \\
\hline & & Gas & 99.7 & NA & NA & 99.1 & 96.4 & 87.2 & 68.2 & 63.4 & 24.6 & 24.0 & 12.1 & 11.1 & 10.4 & 10.2 & NA & 10.9 & \\
\hline \multirow[t]{2}{*}{2} & 2 & Particle & 0.18 & NA & NA & 0.64 & 4.30 & 4.69 & 38.5 & 40.9 & 73.9 & 78.3 & 84.6 & 90.5 & 87.6 & 84.0 & NA & 90.2 & \\
\hline & & Gas & 99.8 & NA & NA & 99.4 & 95.7 & 95.3 & 61.5 & 59.1 & 26.1 & 21.7 & 15.4 & 9.50 & 12.4 & 16.0 & NA & 9.83 & \\
\hline \multirow[t]{2}{*}{3} & 3 & Particle & 0.29 & NA & 0.45 & 0.73 & 3.71 & 10.8 & 30.2 & 38.0 & 71.6 & 74.9 & 80.4 & 82.1 & 80.8 & 78.6 & NA & 82.6 & \\
\hline & & Gas & 99.7 & NA & 99.5 & 99.3 & 96.3 & 89.2 & 69.8 & 62.0 & 28.4 & 25.13 & 19.6 & 17.9 & 19.2 & 21.4 & NA & 17.4 & \\
\hline \multirow[t]{2}{*}{4} & 4 & Particle & 0.17 & 3.44 & 0.55 & 0.40 & 4.25 & 8.47 & 45.98 & 53.06 & 86.2 & 87.5 & 92.4 & 92.4 & 92.8 & 94.0 & 92.7 & 93.8 & \\
\hline & & Gas & 99.8 & 96.6 & 99.4 & 99.6 & 95.8 & 91.5 & 54.0 & 46.9 & 13.8 & 12.5 & 7.60 & 7.60 & 7.20 & 5.99 & 7.30 & 6.18 & \\
\hline \multirow[t]{2}{*}{5} & 5 & Particle & 0.67 & NA & 0.74 & 2.02 & 5.48 & 12.91 & 46.30 & 41.6 & 73.1 & 76.7 & 86.0 & 84.6 & 81.5 & NA & NA & NA & \\
\hline & & Gas & 99 & NA & 99.3 & 98.0 & 94.5 & 87.1 & 53.7 & 58.4 & 26.9 & 23.33 & 14.0 & 15.4 & 18.5 & NA & NA & NA & \\
\hline
\end{tabular}

Table 4. Quantitative analysis of PAHs in ambient air samples collected continuously using the ST/ TD-GC-MS system. Sampling conditions: (1) Sampling point: Ambient air at about the $21 \mathrm{~m}$ level (seventh floor), (2) Mean temp.: $15.7 \pm 2.04{ }^{\circ} \mathrm{C}$, (3) Mean humidity: $72.6 \pm 7.55 \%$, (4) Sampling flow rate: $2 \mathrm{~L} \cdot \mathrm{min}^{-1}$, (5) Sampling time: 12 hours (starting at 00:00 local time), (6) Sampling volume: $1.44 \mathrm{~m}^{3}$, and (7) Sampling period: 7 to 11 Oct. 2011. a Sample code $=$ ST type + Set code (i.e., CC-1 = CC tube sampling of Set

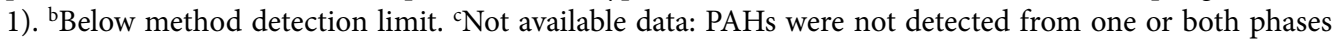
(particle and gas) in air.

The partitioning behavior of PAHs in air between gas and particulate phases. As a means to demonstrate the feasibility of our ST method for PAH analysis, ambient PAH samples were continuously measured using the ST method. The PAH sampling was conducted on the seventh floor of the Jae Sung Engineering Building, HanYang University, for five successive days in Oct. 2014. The QC sampler (QW + CC tubes) was used as sampling media to separately collect the particulate and gaseous PAHs from outdoor air. In addition, triplicate samples of ambient PAHs were also simultaneously collected and analyzed using three QC samplers in order to test the reproducibility (or compatibility) of the QC sampling method.

Table 4 shows the results of the quantitative analysis of 16 target PAHs in ambient air samples collected at daily intervals. During the five sampling days, total PAH concentration (sum of the 16 PAHs) averaged $78.8 \pm 38.2 \mathrm{ng} \cdot \mathrm{m}^{-3}$ (range $(\mathrm{n}=5): 30.1$ (5th day) to $132 \mathrm{ng} \cdot \mathrm{m}^{-3}$ (4th day)). The total PAH concentration 


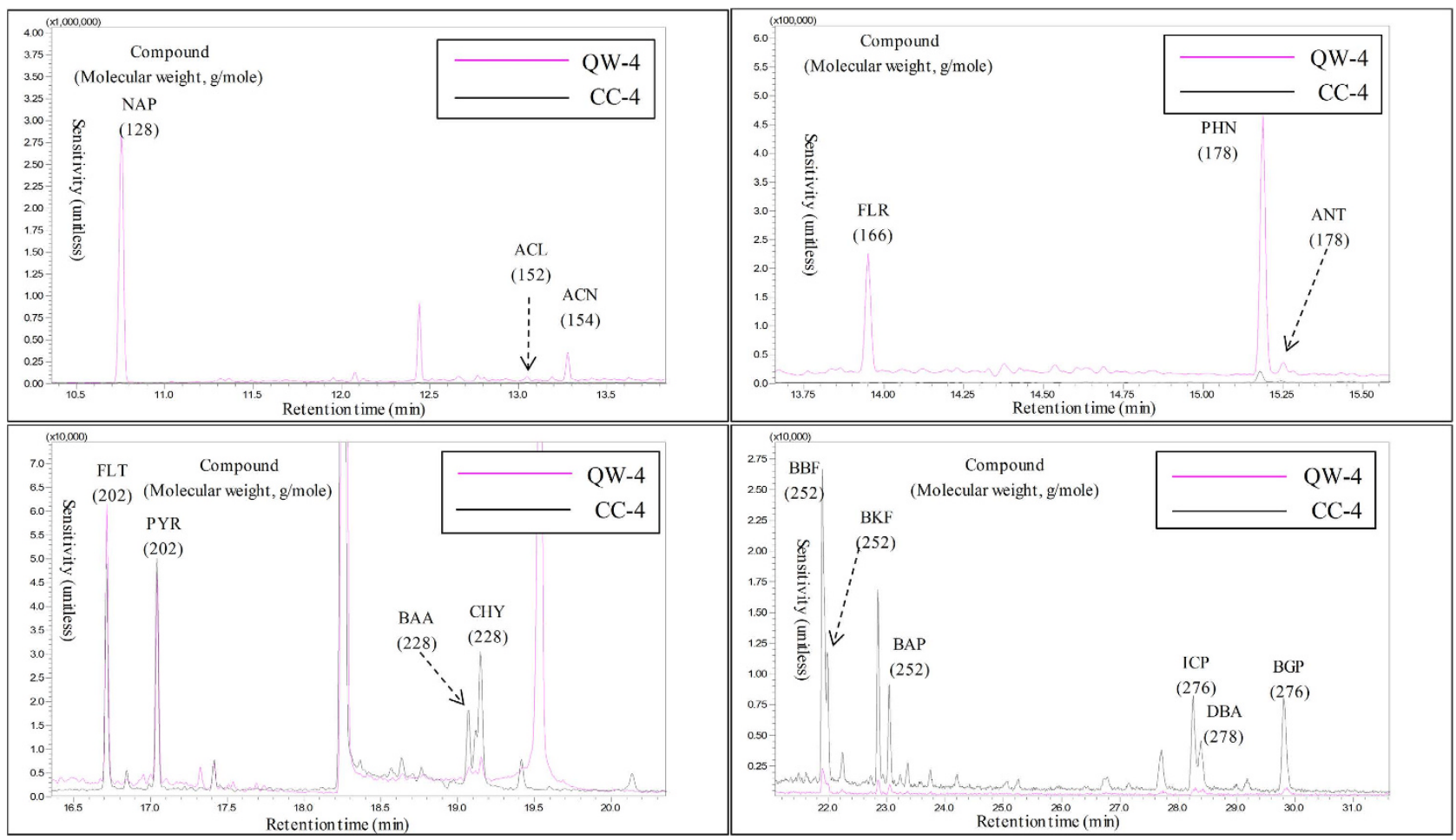

Figure 2. Chromatograms of the 16 PAH measured from ambient air samples collected on the fourth of five consecutive daily runs (Particle (QW-4) vs. gas phases (CC-4)).

data exhibited roughly four-fold variation during these five days. When the relative proportions of individual PAHs were compared against their total concentration, NAP demonstrated the highest value, with a mean of $66.8 \% \pm 7.82 \%$ (Figure S1). Thus, the total PAH concentration was most strongly influenced by the NAP concentration. In contrast, five- to six-ringed PAHs had very low concentrations, typically below $1 \mathrm{ng} \cdot \mathrm{m}^{-3}$. The results of triplicate analyses of ambient PAHs confirmed that NAP was predominant (the relative proportion of NAP $=59.1 \pm 3.34 \%$ ) (Table 4): total PAH concentrations of triplicate analyses (A, B, and C) were 110, 88.4, and $77.6 \mathrm{ng} \cdot \mathrm{m}^{-3}$, respectively (mean: $91.9 \pm 16.2 \mathrm{ng} \cdot \mathrm{m}^{-3}$ ). Although ambient PAHs were sampled at the same time, the total PAH values varied moderately between different samples $(\mathrm{RSE}=10.2 \%)$. However, if the NAP from these triplicate analyses was excluded from the total concentration, the compatibility between triplicates increased greatly to 40.6 (A), 37.9 (B), and 33.2 (C) $\mathrm{ng} \cdot \mathrm{m}^{-3}(\mathrm{RSE}=5.76 \%)($ Table S4). The chromatograms of 16 target PAHs detected from outdoor air are presented in Fig. 2 using the results from the fourth day (10 Oct. 2014).

The target PAHs showed a clear partitioning pattern between gas and particulate phases, especially based on such simple criteria as the number of aromatic rings and/or molecular weight (Figure S2). The two- and three-ringed PAHs existed mainly in the gas-phase (mean gas fraction $=96.6 \% \pm 4.01 \%$ ). In the case of four-ringed PAHs, systematic fractionation was established across the particle/gas boundary. For instance, in the particle fraction, FLT and PYR (molecular weight $=202 \mathrm{~g} / \mathrm{mole}$ ) remained at $40.3 \% \pm 6.90 \%$, while BAA and CHY (molecular weight $=202 \mathrm{~g} /$ mole) were much more abundant (mean $77.4 \% \pm 5.34 \%$ ). All five- and six-ringed PAHs were detected predominantly in the particulate phase (mean particle fraction $=87.4 \pm 4.71 \%$ ). As such, the particle/gas partitioning ratio increased consistently and systematically with increasing molecular weight.

The results of particle-gas partitioning patterns in this study are thus very similar to those reported from many previous studies based on conventional methods (e.g., US EPA methods) (Table 5). Simcik et al. ${ }^{21}$ quantified gaseous and particulate PAHs in outdoor air (sampling sites: (1) Chicago (southwest and north winds) and (2) Lake Michigan (southwest and north winds, USA)) using a glass fiber filter and PUF sampler, respectively. Accordingly, the fraction of three-ringed PAHs (FLR, PHN, and ANT) in the particulate phase averaged $3.03 \% \pm 3.01 \%$, while those of five- and six-ringed PAHs (BBF, BKF, BAP, BGP, and benzo[e]pyrene) comprised a high proportion (mean $88.9 \% \pm 8.90 \%$ ). In the case of four-ringed PAHs, the particulate fractions of $202 \mathrm{~g} / \mathrm{mole}$ (FLT and PYR) and $228 \mathrm{~g} / \mathrm{mole}$ (BAA and CHY) were measured as $15.1 \% \pm 10.4 \%$ and $60.1 \% \pm 12.1 \%$., respectively. Despite differences in experimental approaches compared to our study, the results of Simcik et al. ${ }^{21}$ also showed a systematic fractionation of PAHs in air to be strongly associated with molecular weight. This type of particle-gas partitioning pattern of ambient PAHs was in fact observed not only in Simcik et al. ${ }^{21}$, but also in many other previous studies. Ma et al. ${ }^{13,22}$ analyzed ambient PAHs at Harbin and Beijing, China using an analytical method 


\begin{tabular}{|c|c|c|c|c|c|c|c|}
\hline \multirow[b]{3}{*}{ Order } & \multirow{3}{*}{$\begin{array}{c}\text { Method } \\
\text { code }^{a}\end{array}$} & \multirow[b]{3}{*}{ Phase } & \multicolumn{4}{|c|}{ Mean PAH concentration $\left(\mathbf{n g} \cdot \mathrm{m}^{-3}\right)$} & \multirow[b]{3}{*}{ Ref. } \\
\hline & & & $\Sigma 2-3$ & \multicolumn{2}{|c|}{$\Sigma 4$ rings } & \multirow{2}{*}{$\begin{array}{c}\Sigma 5 \text { - } 6 \\
\text { rings }\end{array}$} & \\
\hline & & & rings & $202 \mathrm{~g} / \mathrm{mole}$ & $228 \mathrm{~g} / \mathrm{mole}$ & & \\
\hline \multirow[t]{3}{*}{1} & T-AbBd- $4-\alpha$ & Particle: & 0.51 & 1.25 & 0.50 & 1.53 & This study (2014) \\
\hline & & Gas: & 72.9 & 1.86 & 0.13 & 0.18 & \\
\hline & & Particle fraction (\%): & 0.69 & 40.3 & 79.9 & 89.3 & \\
\hline \multirow[t]{3}{*}{2} & C-AbBd-1- $\beta$ & Particle: & 1.64 & 5.76 & 8.94 & 31.8 & Yamasaki, et al. ${ }^{29}$ \\
\hline & & Gas: & 147 & 58.1 & 4.16 & 0.71 & \\
\hline & & Particle fraction (\%): & 1.11 & 9.01 & 68.2 & 97.8 & \\
\hline \multirow[t]{3}{*}{3} & C-AbBd-1- $\alpha$ & Particle: & 1.44 & 3.02 & 2.14 & 6.79 & Simcik, et al..$^{21}$ \\
\hline & & Gas: & 60.9 & 16.7 & 1.04 & 0.70 & \\
\hline & & Particle fraction (\%): & 2.31 & 15.3 & 67.3 & 90.7 & \\
\hline \multirow[t]{3}{*}{4} & C-AaBd-1-C & Particle: & 0.31 & 0.47 & 0.14 & 0.72 & Albinet, et al. ${ }^{17}$ \\
\hline & & Gas: & 4.56 & 7.73 & $N D$ & $N D$ & \\
\hline & & Particle fraction (\%): & 6.28 & 5.71 & - & - & \\
\hline \multirow[t]{3}{*}{5} & C-AbBd-1- $\alpha$ & Particle: & 10.5 & 15.7 & 6.76 & 12.3 & Ma, et al. ${ }^{13}$ \\
\hline & & Gas: & 50.0 & 4.15 & 0.19 & 0.04 & \\
\hline & & Particle fraction (\%): & 17.4 & 79.1 & 97.3 & 99.7 & \\
\hline \multirow[t]{3}{*}{6} & C-AbBd-1- $\alpha$ & Particle: & 5.80 & 22.8 & 23.4 & 52.1 & $\mathrm{Ma}$, et al. ${ }^{22}$ \\
\hline & & Gas: & 92.0 & 25.1 & 1.20 & 0.30 & \\
\hline & & Particle fraction (\%): & 5.93 & 47.6 & 95.1 & 99.4 & \\
\hline
\end{tabular}

Table 5. Comparison of the concentration levels of ambient PAHs in different studies. ${ }^{\text {a Method code: }}$ Method type-Phase/Sampler-Pretreatment-Separation/Detection (refer to the Fig. 1).

comparable to that of Simcik et al. ${ }^{21}$ and reported that five- to six-ringed PAHs had high fractionation in the particulate phase (>99\%). In contrast, the particle fractions of two- and three-ringed PAHs were relatively low, with means of $17.4 \%$ and $5.93 \%$, respectively. Albinet et al. ${ }^{17}$ were unable to detect heavy PAHs with more than five aromatic rings in the gas fraction.

\section{Conclusions}

In order to analyze ambient PAHs at sub ng. $\mathrm{m}^{-3}$ levels, large sampling volumes (and long sampling times of up to a few days) and complicated pretreatment procedures (such as extraction, clean-up, and concentration) are required. In addition, the use of an internal standard is required in order to balance low recovery stemming from the loss of analytes due to the complicated pretreatment. In this study, a novel technique for PAH analysis was developed using ST sampling coupled with a TD-GC-MS system and was validated against real ambient air samples. To this end, basic calibration and QA data for PAH analysis were acquired by ST-based analysis. Then, ambient PAH samples were collected continuously over a five day period in October 2014 using the ST and analyzed using a TD-GC-MS system. In addition, to remove the carry-over effect of the ST-based analysis, conditioning of ST was carried out in all stages of PAH analysis.

All 16 target PAHs had fairly good linearity $\left(\mathrm{R}^{2}>0.99\right)$ and reproducibility $(\mathrm{RSE}<1 \%)$ according to the ST-based analysis of the liquid-phase PAH standards. In addition, the MDL values of all PAHs as determined by the ST method were very low, with a mean of $13.1 \mathrm{pg}$. In addition to the simplicity of the ST method (without pretreatment procedures or an internal standard), it is possible to accurately quantify ambient PAHs (at sub ng. $\mathrm{m}^{-3}$ levels) at sufficiently low sampling volume ( $1 \mathrm{~m}^{3}$ level). For a daily ambient sample of $1.44 \mathrm{~m}^{3}$, the total concentration of target PAHs averaged $78.8 \mathrm{ng} \cdot \mathrm{m}^{-3}$ over a five day period. Light PAHs were detected predominantly in the gas phase (sampled by the Carbopack C tube), while heavy PAHs existed mainly in the particulate phase (collected by a quartz wool tube). In the case of BAP, the mean of $0.21 \mathrm{ng} \cdot \mathrm{m}^{-3}$ was detected from the ambient samples, representing a particle fractionation of $86.5 \%$. The four-ringed PAHs showed dynamic fractionation between gas and particulate phases. This study thus successfully demonstrated the feasibility of ST-based sampling and TD-based analysis 

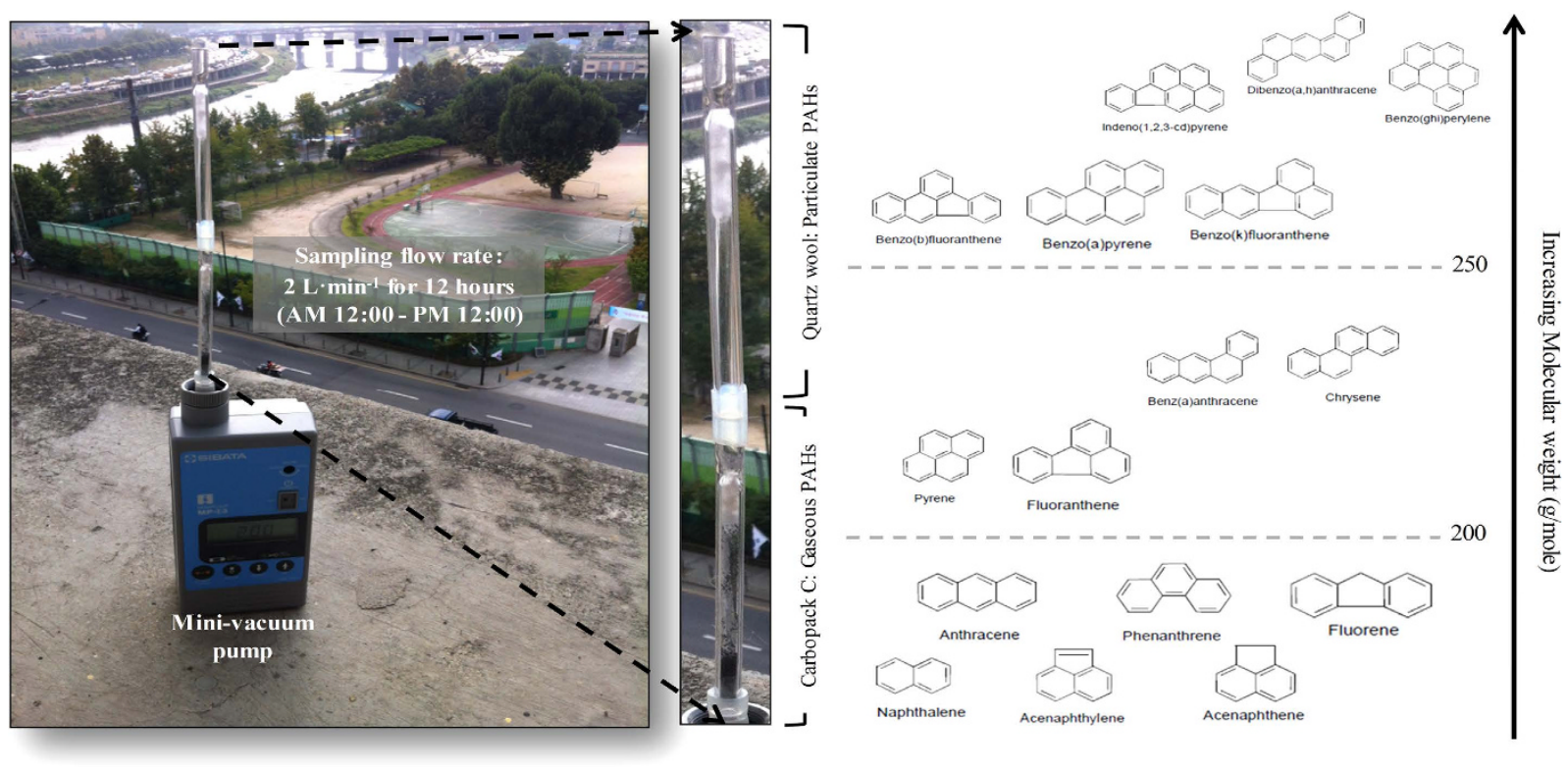

Figure 3. Sampling of PAHs in ambient air using a sorbent tube equipped with a vacuum pump (Sampling point: Seventh floor of the Jae Sung Engineering Building, Seoul, Korea).

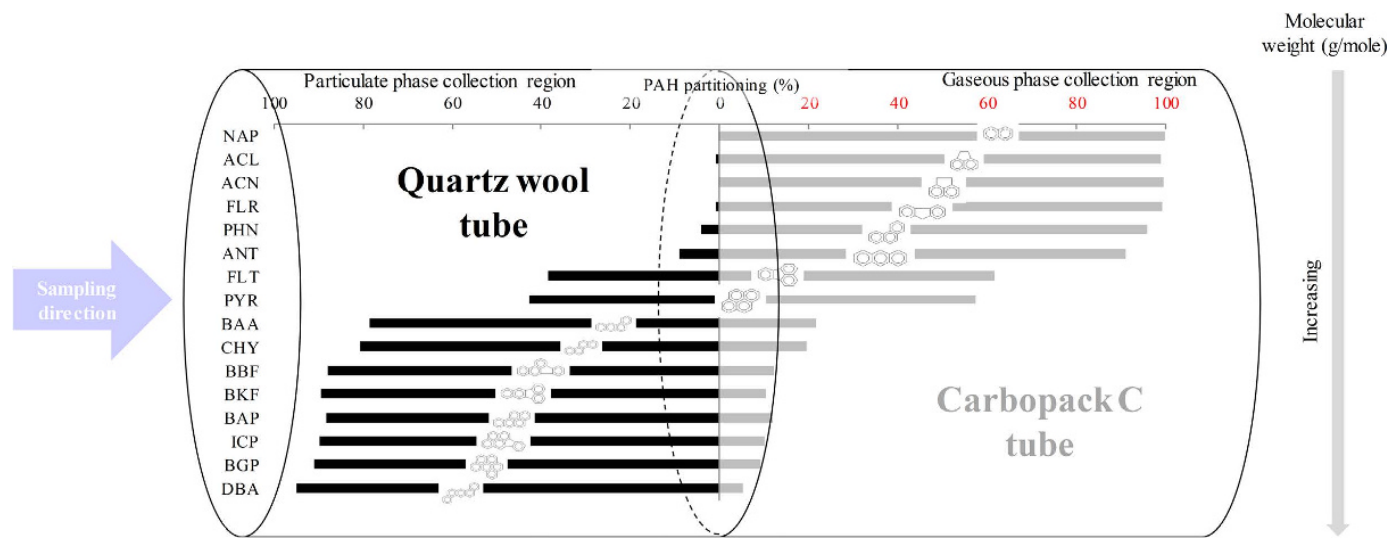

Figure 4. Schematic of the relationship between the QC sampler (combination of quartz wool (QW) and Carbopack C (CC) tubes) and collected PAHs (between particulate and gaseous phases).

for accurate and reliable quantification of PAHs. In addition, for practical application of the ST method, we confirmed that a reasonably small $\left(1 \mathrm{~m}^{3}\right)$ sample volume is sufficient. Due to the thermal desorption procedure employed for $\mathrm{PAH}$ analysis in this study, we were able to simplify the pretreatment procedures for the optimum recovery of the PAHs. This ST method can thus be used to establish a routine monitoring system for PAH and to replace the methods or procedures based on conventional systems.

\section{Methods}

Preparation of liquid PAH standards. A total of 16 PAHs promulgated as priority pollutants by the US EPA were selected as the target analytes in this research (Table S5): (1) naphthalene (NAP), acenaphthylene (ACL), acenaphthene (ACN), fluorene (FLR), phenanthrene (PHN), anthracene (ANT), fluoranthene (FLT), pyrene (PYR), benz[a] anthracene (BAA), chrysene (CHY), benzo[b]fluoranthene (BBF), benzo[k]fluoranthene (BKF), benzo[a]pyrene (BAP), indeno[1,2,3-c,d]pyrene (ICP), dibenz[a,h] anthracene (DBA), and benzo[g,h,i]perylene (BGP). The liquid working PAH standards (L-WS) used for calibration and quality assurance (QA) were prepared by the dilution of EPA 610 Polynuclear Aromatic Hydrocarbon Mixture (Supelco, St. Louis, MO, USA) with methanol. Liquid working standards were produced to cover a relatively wide range of concentration levels (e.g., $\mathrm{BAP}=1.25$ to $49.8 \mathrm{ng} \cdot \mu \mathrm{L}^{-1}$ ) in 2 $\mathrm{mL}$ vials (Table S6). 
Preparation of sorbent tubes. The ST for the collection and analysis of 16 target PAHs was prepared to calibrate L-WS and to quantify real ambient samples. The feasibility of the ST method for PAH analysis has been explored in many previous studies ${ }^{18,23}$. However, the use of ST in those studies was confined to calibration only. Earlier researchers encountered some technical limitations due to the difficulty of increasing sampling volume with an ST sampler, although it is crucial to acquire a sufficient quantity of analytes for detection. Hence, the use of glass or quartz filters adaptable to large volume sampling ( $>$ tens of $\mathrm{m}^{3}$ ) was used in order to expand the sampling capacity of ambient air to the maximum level. Consequently, the application of ST in the TD-based analysis was confined to standard calibration experiments rather than for actual sampling ${ }^{18}$. In light of the physical differences in media used for environmental sampling (filter) and standard calibration (ST), the objectivity of the QA data in previous studies is somewhat questionable ${ }^{18,24,25}$. In the present study, to overcome diverse technical or practical problems encountered in many previous TD-based analyses, we designed a new approach to maintain the compatibility of the sampling methods by employing the same ST for both standard calibration and sample analysis.

In this study, for the collection and analysis of all target PAHs in gas and particle fractions, we prepared two types of ST. The first tube was filled with $50 \mathrm{mg}$ of Carbopack C (60/80, Supelco, USA) applied to $10 \mathrm{mg}$ of quartz wool (Supelco, USA) (the "CC tube"). Carbopack C was selected as the sorbent in order to induce optimal adsorption of gas-phase PAHs ${ }^{26,27}$. The second tube was packed solely with $25 \mathrm{mg}$ of quartz wool (QW tube) and was used to capture particulate PAHs.

Calibration and QA experiments were performed using the CC tube loaded with known quantities of the L-WS containing PAHs. For analysis of real PAH samples in ambient air, collection was performed using serially connected QW and CC tubes (Fig. 3). The resulting tube was called the "QC" tube in order to represent a combination of "QW and CC" in the sampling stage. The front and back fractions of QC were thus used to collect the particulate and gaseous PAHs, respectively (Fig. 4).

Instrumental system. The analysis of PAH samples in this work was carried out using a GC (model: GC-2010, Shimadzu, Japan) connected to an MS (model: GCMS-QP2010 ultra, Shimadzu, Japan) and a thermal desorber (model: TD-20, Shimadzu, Japan). The schematic and operational conditions of the TD system were set to maximize PAH recovery by virtually eliminating the long transfer line for carrying thermally desorbed PAH from the TD to the GC-MS. The PAHs loaded on the ST were thermally desorbed at $290^{\circ} \mathrm{C}(7 \mathrm{~min})$ at a reverse flow of $100 \mathrm{~mL} \cdot \mathrm{min}^{-1}$ of helium $(>99.9999 \%)$ carrier gas. The desorbed analytes were swept into the cold trap (held at $5^{\circ} \mathrm{C}$ ) in the stream of carrier gas. The cold trap packed with quartz wool $(10 \mathrm{mg})$ and Tenax TA $(50 \mathrm{mg})$ in a Silcosteel holder (Shimadzu, Japan) was then rapidly desorbed $\left(300^{\circ} \mathrm{C}\right.$ for $5 \mathrm{~min}$ ) in a reverse flow of carrier gas in order to transfer (inject) the target PAHs into the column (DB-5ms - length: $30 \mathrm{~m}$, diameter: $0.25 \mathrm{~mm}$, and thickness: $0.25 \mu \mathrm{m}$, Agilent, USA). The transfer/injection of analytes from the cold trap into the GC column was carried out by splitting the flow between the column $\left(2 \mathrm{~mL} \cdot \mathrm{min}^{-1}\right)$ and the split vent $\left(10 \mathrm{~mL} \cdot \mathrm{min}^{-1}\right)$. The oven temperature was initially set at $80^{\circ} \mathrm{C}$ (for $5 \mathrm{~min}$ ), ramped at $20^{\circ} \mathrm{C} \cdot \mathrm{min}^{-1}$ to $300^{\circ} \mathrm{C}$, and held at this temperature for $24 \mathrm{~min}$ (a total run time of $40 \mathrm{~min}$ ).

To detect all 16 target PAHs, the interface and ion source temperatures were set relatively high (e.g., at $280^{\circ} \mathrm{C}$ ) in order to prevent contamination in the MS system. The PAHs were initially analyzed in total ion chromatographic (TIC) mode over a mass range of 35 to $600 \mathrm{~m} / \mathrm{z}$. Extracted ion chromatographic (EIC) mode was subsequently applied to minimize interference and to maximize the sensitivity using significant ions identified from the spectrum of each PAH (Table S5). Detailed information on the instrumental system is included in Table 1 .

Experimental approaches. For the calibration and QA-related experiments, the L-WS containing 16 target PAHs was injected directly into the CC tube and analyzed using the TD-GC-MS system (Figure S3). The CC tube is stronger adsorbent than QW tube. As the analysis of CC tube is expected to show the maximum recovery of $\mathrm{PAH}$, our calibration exp was conducted by $\mathrm{CC}$ tube only ${ }^{27}$. The inlet of the CC tube was connected to a gas cylinder containing ultra-pure nitrogen $(>99.999 \%)$. A Teflon tube was used to connect the ST and the gas cylinder. Then, $1 \mu \mathrm{L}$ of the L-WS was injected onto the CC tube via a temporary injection port made from the Teflon tube that connected the inlet of the CC tube and the gas cylinder. The nitrogen gas in the gas cylinder was then delivered to the CC tube (flow rate $=3 \mathrm{~L} \cdot \mathrm{min}^{-1}$ for $3 \mathrm{~min}$ ). The PAHs loaded on the CC tube were then desorbed using the TD system prior to separation by the GC and final detection by the MS.

The collection of PAH in real ambient air samples was carried out by two-stage sampling with the aid of the QC sampler. This sampler was created as a combination of serially connected QW (front) and CC (back) tubes for collecting particulate and gaseous PAHs, respectively (Fig. 3). The particulate PAHs were first introduced into the QW tube placed at the front, and the gaseous PAHs penetrating the QW tube were then collected by the CC tube (Fig. 4). The outlet of each QC tube was connected to the vacuum pump that interfaced with a mass flow controller (MFC) (Sibata $\Sigma$ MP-300, Japan). To measure the gas/particle fractionation of PAHs in air, two types of ST (QW and CC) were used simultaneously as PAH sampling media. However, they were desorbed individually for the analysis of PAH partitioned to each individual fraction. The PAH sampling from outdoor air was conducted on the seventh floor 
(about $21 \mathrm{~m}$ ) of Jae Sung Engineering Building (HanYang University, Seoul, Korea) for a period of five consecutive days ( 7 to 11 Oct. 2014). The collection of PAH samples continued for 12 hours starting at midnight (flow rate $=2 \mathrm{~L} \cdot \mathrm{min}^{-1}$ and total sampling volume $\left.=1.44 \mathrm{~m}^{3}\right)($ Fig. 3). For QC tubes, five code numbers, $1,2,3,4$, and 5 , were assigned to samples obtained for each of five days. The sample codes were further categorized by assigning a number (order of day) and tube type (QW or QC) such as QW (QW-1, QW-2, QW-3, QW-4, and QW-5) and CC (CC-1, CC-2, CC-3, CC-4, and CC-5). In addition, to test the reliability of QC sampling, triplicate samples of ambient PAHs were simultaneously collected using three QC samplers (Set code: A, B, and C) on 7 Sept. 2014 (sample codes: QW (QW-A, QW-B, and $\mathrm{QW}-\mathrm{C}$ ) and $\mathrm{CC}$ (CC-A, CC-B, and CC-C)).

In ST analysis, the breakthrough (BT) volume is one of the key criteria for accurate quantification. In this study, a total volume of $1.44 \mathrm{~m}^{3}$ ambient sample was collected at $2 \mathrm{~L} \cdot \mathrm{min}^{-1}$ for 12 hours. The occurrence of $\mathrm{BT}$ on the $\mathrm{CC}$ tube was examined by increasing the sampling volume of ambient PAH. To this end, the third calibration point of the L-WS $\left(\mathrm{BAP}=4.98 \mathrm{ng} \cdot \mu \mathrm{L}^{-1}\right)$ was injected onto the CC tube and purged with nitrogen gas up to $2,520 \mathrm{~L}$ at a fixed flow rate of $3 \mathrm{~L} \cdot \mathrm{min}^{-1}$ (six volumes tested between 1 and $2,520 \mathrm{~L}$ ). The procedures for BT test using the L-WS were adopted from those used for the analysis of the L-WS but at varying purge volumes (by controlling the purge times). After this purge stage, the CC tubes were analyzed using a TD-GC-MS system.

\section{References}

1. Jones, K. C., Grimmer, G., Jacob, J. \& Johnston, A. E. Changes in the Polynuclear Aromatic Hydrocarbon Content of WheatGrain and Pasture Grassland over the Last Century from One Site in the Uk. Sci. Total Environ. 78, 117-130 (1989).

2. International Agency for Research on Cancer (IARC). Overall evaluations of carcinogenicity, IARC monography. Vol. 1 to 34 (Lyon, France, 1987).

3. International Agency for Research on Cancer (IARC). Polynuclear Aromatic Compounds: Part 3, Industrial Exposures, IARC monography. Vol. 34 (Lyon, France, 1984).

4. Maliszewska-Kordybach, B. Sources concentrations, fate and effects of polycyclic aromatic hydrocarbons (PAHs) in the environment. Part A: PAHs in air. Pol. J. Environ. Stud. 8, 131-136 (1999).

5. Brown, A. S. \& Brown, R. J. Correlations in polycyclic aromatic hydrocarbon (PAH) concentrations in UK ambient air and implications for source apportionment. J. Environ. Monitor. 14, 2072-2082 (2012).

6. U.S. EPA. Determination of Polynuclear Aromatic Hydrocarbons in Solid Waste by Gas Chromatography, US EPA Method 8100 (US Government Printing Office, Washington DC, USA, 1986).

7. U.S. EPA. Determination of Polynuclear Aromatic Hydrocarbons in ground water and wastes by Liquid Chromatography, US EPA Method 8310 (US Government Printing Office, Washington DC, USA, 1986).

8. U.S. EPA. Determination of Pesticides and Polychlorinated Biphenyls in Ambient Air Using High Volume Polyurethane Foam (PUF) Sampling Followed by Gas Chromatographic/Multi-Detector Detection (GC/MD), Compendium Method TO-4A, 2nd edn (Cincinnati, OH 45268, 1999).

9. U.S. EPA. Determination of Polycyclic Aromatic Hydrocarbons (PAHs) in Ambient Air Using Gas Chromatography/Mass Spectrometry (GC/MD), Compendium Method TO-13A, 2nd edn (Cincinnati, OH 45268, 1999).

10. U.S. EPA. Parent And Alkyl Polycyclic Aromatics in Sediment Pore Water by Solid-Phase Microextraction and Gas Chromathography/Mass Spectrometry in Selected Ion Monitoring mode, ss-846 Method 8272 (2007) Available at: http://www. epa.gov/solidwaste/hazard/testmethods/pdfs/8272.pdf (Accessed: 14 May 2015)

11. Foley, J. P. \& Dorsey, J. G. Clarification of the Limit of Detection in Chromatography. Chromatographia 18, 503-511 (1984).

12. Kim, Y.-H. \& Kim, K.-H. Ultimate Detectability of Volatile Organic Compounds: How Much Further Can We Reduce Their Ambient Air Sample Volumes for Analysis? Anal. Chem. 84, 8284-8293 (2012).

13. Ma, W. L. et al. Seasonal variations of sources of polycyclic aromatic hydrocarbons (PAHs) to a northeastern urban city, China. Chemosphere 79, 441-447 (2010).

14. Anthwal, A., Jung, K., Kim, H. J., Bae, I. S. \& Kim, K.-H. Polycyclic Aromatic Hydrocarbons in Ambient Air at Four Urban Locations of Seoul, Korea. Fresen. Environ. Bull. 19, 1356-1368 (2010).

15. Bari, M. A., Baumbach, G., Kuch, B. \& Scheffknecht, G. Particle-phase concentrations of polycyclic aromatic hydrocarbons in ambient air of rural residential areas in southern Germany. Air Qual. Atmos. Hlth. 3, 103-116 (2010).

16. Okuda, T. et al. Polycyclic aromatic hydrocarbons (PAHs) in the aerosol in Beijing, China, measured by aminopropylsilane chemically-bonded stationary-phase column chromatography and HPLC/fluorescence detection. Chemosphere 65, 427-435 (2006).

17. Albinet, A., Leoz-Garziandia, E., Budzinski, H. \& Villenave, E. Polycyclic aromatic hydrocarbons (PAHs), nitrated PAHs and oxygenated PAHs in ambient air of the Marseilles area (South of France): Concentrations and sources. Sci. Total Environ. 384, 280-292 (2007)

18. Bates, M. et al. Analysis of polycyclic aromatic hydrocarbons (PAHs) in airborne particles by direct sample introduction thermal desorption GC/MS. Atmos. Environ. 42, 6144-6151 (2008).

19. Wauters, E. et al. Improved accuracy in the determination of polycyclic aromatic hydrocarbons in air using $24 \mathrm{~h}$ sampling on a mixed bed followed by thermal desorption capillary gas chromatography-mass spectrometry. J. Chromatogr. A 1190, 286-293 (2008).

20. Lazarov, B. et al. Optimisation steps of an innovative air sampling method for semi volatile organic compounds. Atmos. Environ. 79, 780-786 (2013).

21. Simcik, M. F., Franz, T. P., Zhang, H. X. \& Eisenreich, S. J. Gas-particle partitioning of PCBs and PAHs in the Chicago urban and adjacent coastal atmosphere: States of equilibrium. Environ. Sci. Technol. 32, 251-257 (1998).

22. Ma, W.-L. et al. Atmospheric concentrations, sources and gas-particle partitioning of PAHs in Beijing after the 29th Olympic Games. Environ. Pollut. 159, 1794-1801 (2011).

23. Buchet, J.-P. et al. Evaluation of exposure to polycyclic aromatic hydrocarbons in a coke production and a graphite electrode manufacturing plant: assessment of urinary excretion of 1-hydroxypyrene as a biological indicator of exposure. Brit. J. Ind. Med. 49, 761-768 (1992).

24. Falkovich, A. H. \& Rudich, Y. Analysis of semivolatile organic compounds in atmospheric aerosols by direct sample introduction thermal desorption GC/MS. Environ. Sci. Technol. 35, 2326-2333 (2001).

25. Robbat, A., Liu, T. Y. \& Abraham, B. M. On-Site Detection of Polycyclic Aromatic-Hydrocarbons in Contaminated Soils by Thermal-Desorption Gas-Chromatography Mass-Spectrometry. Anal. Chem. 64, 1477-1483 (1992). 
26. Kim, Y.-H. \& Kim, K.-H. Novel Approach to Test the Relative Recovery of Liquid-Phase Standard in Sorbent-Tube Analysis of Gaseous Volatile Organic Compounds. Anal. Chem. 84, 4126-4139 (2012).

27. Woolfenden, E. Sorbent-based sampling methods for volatile and semi-volatile organic compounds in air. Part 2. Sorbent selection and other aspects of optimizing air monitoring methods. J. Chromatogr. A 1217, 2685-2694 (2010).

28. Sheu, H.-L., Lee, W.-J., Su, C.-C., Chao, H.-R. \& Fan, Y.-C. Dry deposition of polycyclic aromatic hydrocarbons in ambient air. J. Environ. Eng. 122, 1101-1109 (1996).

29. Yamasaki, H., Kuwata, K. \& Miyamoto, H. Effects of ambient temperature on aspects of airborne polycyclic aromatic hydrocarbons. Environ. Sci. Technol. 16, 189-194 (1982).

30. Menezes, H. C. \& de Lourdes Cardeal, Z. Determination of polycyclic aromatic hydrocarbons from ambient air particulate matter using a cold fiber solid phase microextraction gas chromatography-mass spectrometry method. J. Chromatogr. A 1218, 33003305 (2011).

31. Schnelle-Kreis, J., Gebefügi, I., Welzl, G., Jaensch, T. \& Kettrup, A. Occurrence of particle-associated polycyclic aromatic compounds in ambient air of the city of Munich. Atmos. Environ. 35, S71-S81 (2001).

\section{Acknowledgements}

This research was supported by a grant (14182MFDS977) from the Ministry of Food and Drug Safety, Korea in 2015. We also acknowledge partial support made by a grant from the National Research Foundation of Korea (NRF) funded by the Ministry of Education, Science and Technology (MEST) (No. 2009-0093848).

\section{Author Contributions}

Kim, Y.-H. and Kim, K.-H. wrote the main manuscript text and prepared all tables (1-5) and figures (1-4). Kim, Y.-H. and Kim, K.-H. also prepared supplementary information including supplementary tables (1-6) and figures (1-3). Kim, Y.-H. prepared all sorbent tube samplers and polycyclic aromatic hydrocarbon standards. Kim Y.-H. conducted the sampling and analysis of the all polycyclic aromatic hydrocarbon samples using sorbent tube/thermal desorber-gas chromatography-mass spectrometry.

\section{Additional Information \\ Supplementary information accompanies this paper at http://www.nature.com/srep \\ Competing financial interests: The authors declare no competing financial interests.}

How to cite this article: Kim, Y.-H. and Kim, K.-H. A simple methodological validation of the gas/ particle fractionation of polycyclic aromatic hydrocarbons in ambient air. Sci. Rep. 5, 11679; doi: 10.1038/srep11679 (2015).

(c) (i) This work is licensed under a Creative Commons Attribution 4.0 International License. The images or other third party material in this article are included in the article's Creative Commons license, unless indicated otherwise in the credit line; if the material is not included under the Creative Commons license, users will need to obtain permission from the license holder to reproduce the material. To view a copy of this license, visit http://creativecommons.org/licenses/by/4.0/ 